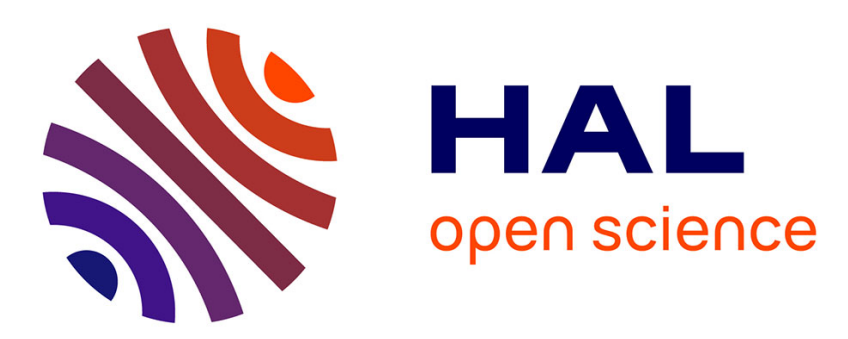

\title{
Orthographic learning during reading: the role of whole-word visual processing
}

Marie-Line Bosse, Nathalie Chaves, Pierre Largy, Sylviane Valdois

\section{To cite this version:}

Marie-Line Bosse, Nathalie Chaves, Pierre Largy, Sylviane Valdois. Orthographic learning during reading: the role of whole-word visual processing. Journal of Research in Reading, 2015, 38, pp.141158. 10.1111/j.1467-9817.2012.01551.x . hal-01218316

\section{HAL Id: hal-01218316 \\ https://hal.science/hal-01218316}

Submitted on 22 Oct 2015

HAL is a multi-disciplinary open access archive for the deposit and dissemination of scientific research documents, whether they are published or not. The documents may come from teaching and research institutions in France or abroad, or from public or private research centers.
L'archive ouverte pluridisciplinaire HAL, est destinée au dépôt et à la diffusion de documents scientifiques de niveau recherche, publiés ou non, émanant des établissements d'enseignement et de recherche français ou étrangers, des laboratoires publics ou privés. 


\title{
ORTHOGRAPHIC LEARNING DURING READING: THE ROLE OF WHOLE- WORD VISUAL PROCESSING
}

\author{
Bosse, Marie-line*, Chaves, Nathalie**, Largy, Pierre**, \& Valdois, Sylviane* \\ *Laboratoire de Psychologie et NeuroCognition - CNRS UMR 5105, Université Pierre \\ Mendès France - Grenoble, France \\ **Laboratoire de Psychologie du Développement et Processus de Socialisation - EA \\ 1687, Université Toulouse II le Mirail - Toulouse, France
}




\begin{abstract}
The self-teaching hypothesis suggests that knowledge about the orthographic structure of words is acquired incidentally during reading through phonological recoding. The current study assessed whether visual processing skills during reading further contribute to orthographic learning. French children were asked to read pseudo-words. The whole pseudo-word letter-string was available at once for half of the targets while the pseudoword's sub-lexical units were discovered in turn for the other half. Then memorisation of the targets orthographic form was assessed. Although most pseudo-words were accurately decoded, target orthographic forms were recognised more often when the pseudo-words entire orthographic sequence was available at once during the learning phase. The wholeword presentation effect was significant and stable from $3^{\text {rd }}$ to $5^{\text {th }}$ grades. This effect was affected neither by target reading accuracy nor by target reading speed during the learning phase. Results suggest that beyond recoding skills, the ability to process the entire orthographic letter string at once during reading contributes to efficient orthographic learning.
\end{abstract}

Keywords

Self-teaching; Orthographic learning; Visual attention span; Visual processing; Phonological processing 


\section{Introduction}

Learning to read and spell relies on the acquisition of at least two types of knowledge. First, the acquisition of decoding skills is required not only for processing newly encountered words in reading but also to generate phonologically plausible orthographic strings in spelling. However, the acquisition of word-specific orthographic knowledge is further required to read fluently and effortlessly (as skilled readers do) and to spell most words correctly, at least in non-transparent languages as French or English. Although the acquisition of decoding skills has been extensively studied in the last decades, the acquisition of word-specific orthographic knowledge remains largely underspecified and is presently a central issue in literacy research (Castles \& Nation, 2006, 2008).

The acquisition of specific orthographic knowledge is typically viewed as depending on the establishment of associations between written and spoken forms of words (Ehri, 2005; Share, 1995; Stanovich, 1993). In practice, two situations favour this association: firstly, the direct-instruction situation (Share, 1995), when the child sees the written form and the teacher or another expert reader provides its corresponding spoken form; and secondly, the self-teaching situation, when the child is able to decode the written form and generate the corresponding spoken form. The direct-instruction situation typically occurs at the beginning of reading acquisition but as the child acquires decoding skills, it tends to disappear and is then replaced by the self-teaching situation. The selfteaching hypothesis (Jorm \& Share, 1983; Share, 1995) assumes that self-teaching is the main way to acquire word-specific orthographic knowledge. According to this hypothesis, the ability to translate unfamiliar printed words into their spoken equivalents is the central means by which orthographic knowledge is acquired. By this account, 
phonological recoding (i.e., reading using knowledge on grapheme-phoneme relations) acts as a self-teaching device, enabling a child to independently develop the wordspecific orthographic knowledge necessary for skilled reading. After a newly encountered word has been decoded successfully, a small number of successful encounters with the same word are sufficient to memorise its orthographic form in long-term memory.

A growing body of empirical studies has investigated orthographic learning during self-teaching (Bowey \& Muller, 2005; Cunningham, 2006; Cunningham, Perry, Stanovich, \& Share, 2002; Kyte \& Johnson, 2006; Martin-Chang, Levy, \& O'Neil, 2007; Nation, Angell, \& Castles, 2007; Share, 1999; Share, 2004). Most studies used variations of the self-teaching paradigm initially developed by Share (1999) in which children are asked to read novel words embedded in short stories (e.g., Share, 1999, experiment 1) or in isolation (e.g., Share, 1999, experiments 2 and 3). After a varying delay, the child's word-specific orthographic knowledge is tested through recognition, spelling and/or reading tasks. All these studies provided evidence for the central aspects of the selfteaching hypothesis, in showing a relation between phonological recoding skills and orthographic learning. Moreover, orthographic learning was found to be attenuated in conditions designed to minimise phonological recoding (Kyte \& Johnson, 2006; Share, 1999), thus providing further support for the view that phonological recoding is critical to the acquisition of word-specific orthographic knowledge, as proposed by the selfteaching hypothesis.

However, there is evidence that phonological decoding cannot be the only factor related to orthographic learning during self-teaching. Nation et al. (2007) showed that the relation between phonological decoding and orthographic learning did not hold at an 
item-by-item level of analysis. They indeed found that a good proportion of novel words, which were accurately recognised in the orthographic choice task, had not been read accurately during the learning phase, and vice versa that a good proportion of items were decoded correctly but not recognized, thus suggesting that there are factors involved in orthographic learning beyond the ability to phonologically decode novel words correctly (see however Share, 2008). Similarly, Share (2004) reported that Hebrew-learning first graders, despite adequate decoding skills, exhibited no evidence of orthographic learning after several exposures to new words (see however Cunningham, 2006). Lastly, when investigating the relation between self-teaching and several abilities other than decoding skills, some studies showed that prior orthographic knowledge (as measured using spelling choice tasks) significantly contributed to orthographic learning during selfteaching after controlling for decoding skills (Cunningham, 2006; Cunningham et al., 2002; Nation et al., 2007). Importantly, these results suggest that orthographic learning during self-teaching is not entirely parasitic on phonological processing abilities. However, they give few insights into what the other cognitive factors involved in orthographic learning could be. These findings are just evidence that, for the same level of decoding abilities, children who had been able to develop more specific orthographic knowledge during their literacy experience are also those who better memorise the orthographic forms of new words when reading in a self-teaching paradigm. Therefore, one remaining key issue is: What cognitive factor(s), other than decoding skills, allow(s) some children to develop lexical orthographic knowledge better than others?

It has already been suggested that differences in visual/orthographic processing might determine self-teaching as a secondary source of variance (Cunningham et al., 
2002; Share, 1995, 1999). The literature on deaf people provides support for visual processing in promoting orthographic learning, showing that some deaf children do achieve correct levels of reading proficiency by relying on visual processing for orthographic learning, despite poor decoding skills (Beech \& Harris, 1997; Paul, 2001). The effect of visual processing on orthographic acquisition has been straightforwardly addressed by Martens and de Jong (2006), using mixed-case words (e.g., WoRd). Case mixing has been shown to hamper word recognition, an effect attributed to the disruption of multi-letter visual units (Mayall, Humphreys, \& Olson, 1997). This disruption might induce serial letter-by-letter processing and be responsible for an increase in attentional demands (Mayall, Humphreys, Mechelli, Olson, \& Price, 2001). In Martens and de Jong's (2006) experiment, children repeatedly read pseudo-words presented in either mixed-case or lower-case during the learning phase. One day after this training phase, lower-case pseudo-words were recognised faster after lower-case training than after mixed-case training. Results thus suggest that disrupting visual multi-letter processing of words affects orthographic knowledge acquisition. As a whole, these findings suggest a role of visual processing in lexical orthographic learning. However, the precise nature of the visual/orthographic processing mechanism involved in orthographic learning remains unclear (see Castles \& Nation, 2006 for a detailed discussion). Obviously, some form of visual-orthographic processing is involved in phonological recoding as well so that successful decoding reflects good visual-to-phonology mapping of the relevant orthographic units. Recent theoretical and empirical data however suggests that, in addition to phonological recoding skills and grapheme visual processing, whole-word 
visual attentional processing might be a second key factor contributing to orthographic learning.

Whole-word visual attentional processing refers to the simultaneous processing of all the orthographic units of a word. This simultaneous processing relates to the visual attention span (Bosse, Tainturier, \& Valdois, 2007) and has to be distinguished from other visual spans such as the perceptual span defined by Rayner (e.g., Rayner, 1986; see Bosse \& Valdois, 2009, for a discussion about differences between perceptual span and visual attention span). The visual attention span is itself based on the connectionist multi-trace memory (hereafter MTM) model of polysyllabic word reading (Ans, Carbonnel, \& Valdois, 1998). An essential feature of the model is the inclusion of a visual attentional window through which orthographic information is extracted from the to-be-read letterstring. The model further postulates the existence of two reading modes: global and analytic. In the global reading mode involved in familiar word processing, the visual attentional window extends over the whole sequence of the word to be read. Global processing typically fails for unfamiliar words that are then processed analytically. In the analytic reading mode, the attentional window narrows down to focus attention on the first relevant unit of the orthographic string. Analytic processing then proceeds through a narrow visual attentional window that shifts from left to right, focusing attention on the different orthographic units of the input in turn. Type of processing thus relies on the size of the visual attentional window which is typically larger for familiar word than for unfamiliar word processing. Although the model has not yet been adapted to simulate acquisition, it provides new insights on the way visual abilities might impact on reading and orthographic acquisition (Valdois, Bosse, \& Tainturier, 2004). In the network, a new 
word memory trace is created each time the entire orthographic input and the entire phonological output of the item are simultaneously available. This would happen in both the direct-instruction situation and the self-teaching situation. In situations of selfteaching, availability of the whole phonological form depends on the ability to decode the novel word by analytic processing. Availability of the entire orthographic input is conditioned by the visual attentional window's ability to extend over the whole word letter string. A visual attentional window large enough to hold the entire word sequence is then required for the acquisition of word-specific orthographic information. Decoding skills, relying on small orthographic unit processing, might be efficient at a time when the visual attentional window is not mature enough to efficiently process the entire word orthographic sequence. In such a case, the entire orthographic input and the entire phonological output of the item wouldn't be simultaneously available and then the word memory trace would not be created. Accordingly, although phonological recoding is critical for the acquisition of orthographic knowledge, the ability to spread visual attention over the whole word letter string might predict word-specific orthographic learning beyond the contribution of phonological recoding skills.

Visual parallel processing abilities have been investigated in dyslexic children within the framework of the visual attention span disorder hypothesis (Bosse et al., 2007). Poor visual attention span abilities - thus poor multi-element visual parallel processing (Lassus-Sangosse, N'Guyen-Morel, \& Valdois, 2008)-- in dyslexic children were found to account for the children's poor reading outcome independently of their phonological skills. Bosse and Valdois (2009) further explored whether visual attention span abilities contributed to the development of reading skills in first, third and fifth graders. They 
showed not only that visual attention span ability increased with reading expertise but also that visual parallel processing ability more specifically related to performance in irregular word reading, which relies on lexical orthographic knowledge. Namely, the unique contribution of the visual attention span to reading remained large and stable over grades for irregular words but decreased sharply from the first grade to later grades for both regular words and pseudo-words. This latter result suggests some specific influence of parallel visual processing on lexical orthographic knowledge acquisition. To sum up, both the MTM model and available empirical data suggest that lexical orthographic learning might rely not only on decoding skills but also on the child's ability to process the entire letter string of the word in parallel. However, the need to process the entire letter sequence of the word simultaneously for acquiring specific orthographic knowledge remains to be experimentally explored.

The main goal of the present study was to determine whether orthographic learning during self-teaching in part relied on simultaneous processing of the entire orthographic word sequence. To test this hypothesis, the experiment directly manipulated the amount of orthographic information available during processing. As in the classical self-teaching paradigm, participants had to read novel words and were later evaluated on their orthographic knowledge of these words. We assessed the effect of simultaneous processing of the entire orthographic word sequence by comparing orthographic learning of novel words under two conditions: In the whole word condition, the entire letter-string of the novel word was available during processing while in the partial word condition, only sub-lexical parts of the word letter-string were available at a time. We reasoned that 
if visual processing of the whole-word orthographic sequence is crucial for specific orthographic learning then, preventing simultaneous processing of the entire word string while preserving accurate phonological decoding would affect orthographic learning. This hypothesis was assessed across three different grades (third to fifth grades). Higher graders were expected to learn orthographic patterns more easily because of their longer learning experience. As visual attention span ability is known to increase with grade (Bosse \& Valdois, 2009), we also expected a larger learning condition effect in older children.

\section{EXPERIMENT}

Method

\section{$\underline{\text { Participants }}$}

A total of 88 French children participated in the experiment. They were recruited from four schools in the Toulouse area (France). This sample consisted of 31 third graders (mean age $=8$ years 8 months, $\mathrm{SD}=4$ months), 28 fourth graders (mean age $=9$ years 3 months, $\mathrm{SD}=4$ months), and 29 fifth graders (mean age $=10$ years 7 months, $\mathrm{SD}$ $=5$ months). They scored on the average on the Raven Standard Progressive Matrices (Raven, Court, \& Raven, 1998), which measure non-verbal reasoning ability (mean percentile $=62$ th $).$ Mean percentile was equivalent among grades: $61.1(\mathrm{SD}=23.15)$, $57.5(\mathrm{SD}=24.3)$ and $68.4(\mathrm{SD}=22.5)$ respectively for grades 3,4 and $5,(\mathrm{~F}(2,85)=1.6$, N.S.). Their mean reading age (Lefavrais, 1965) was 8 years 6 months (SD $=13$ months, range $=7 ; 2-12 ; 2)$ in third grade, 10 years 1 month $(\mathrm{SD}=18$ months, range $=8.0-13 ; 3)$ 
in fourth grade, and 10 years 4 months $(\mathrm{SD}=18$ months, range $=8 ; 4-13 ; 10)$ in fifth grade. Reading age significantly improved across grades $(F(2,85)=13.7, p<.0001)$.

\section{Experimental material}

\section{Target pseudo-words}

Twenty-eight (i.e., 14 pairs) bisyllabic pseudo-words (see Appendix) ranging in length from 5 to 9 letters $(\mathrm{M}=7.1, \mathrm{SD}=0.9)$ were designed. No pseudo-word sounded like a real word or contained a syllable that constituted a real written word. All pseudowords contained two complex graphemes, one in each syllable. The complex graphemes were made of 2.2 letters $(\mathrm{SD}=.6$, range $1-3)$ on average. Ten complex graphemes represented a vocalic phoneme, 14 a consonantal phoneme, and 4 a combination of 2 phonemes (/Ri/ for $r h i$ and $r y, / o n /$ for onn and aun).

The 28 pseudo-words were divided into two sets (see Appendix). Each set comprised the same 14 phonological target pseudo-words, but with a different spelling (e.g., /pofu/ is pauffou in set A and pôphou in set B), so that each set contained 28 complex graphemes. Each set was further divided into two subsets so that the two complex graphemes coding for the same phoneme always appeared in different subsets (see Appendix).

\section{Pseudo-words' presentation: window size manipulation}

In the learning phase, each child had to read aloud target pseudo-words presented in isolation on the computer screen. Half of the targets were seen in large window condition (LW) and the other half in small window condition (SW). Window size was 
counterbalanced across subsets. The fourteen pseudo-words of each set appeared 4 times each in a random order, in black (bold courier new font, size 24) at the centre of the white screen. A central fixation point was first displayed for one second. At the offset of the fixation point, the first syllable of the target was displayed (first screen of Figure 1) and the child had to read it silently, before pressing the space bar. Then, either the second syllable appeared with the first one (LW condition, second screen of Figure 1a), or the second syllable appeared while the first disappeared and was replaced by a mask (SW condition, second screen of Figure 1b). In both conditions, the child had to pronounce the whole pseudo-word phonological sequence as soon as possible from the onset of the second syllable. The second screen disappeared when the child began to pronounce the pseudo-word, and was replaced by a mask for $1500 \mathrm{~ms}$. Target presentation was computed with E-prime software (version 1.1; Schneider, Eschman, \& Zuccolotto, 2002) and a voice key was used to manage second screen disappearance.

Insert Figure 1 about here

\section{Orthographic learning assessment}

Following the training phase during which children read half of the 14 targets in LW condition and the other half in SW condition, two tasks were administered to assess orthographic learning: a spelling to dictation task and an orthographic choice task. These two tasks are typically used in the self-teaching paradigm, as two tests of word-specific orthographic knowledge. Although they differ in their degree of difficulty (e.g., Bosman \& Van Orden, 1997) - since the spelling to dictation task is a reminder task while the orthographic choice task is an easier recognition task (see Rapp \& Lipka, 2011, for a 
recent discussion of the relationship between reading and spelling) — they both address the same cognitive skill. We thus used them as providing evidence for new (pseudo)words' orthographic learning.

\section{Spelling to dictation task}

Children were provided with the target pseudo-word orally and asked to spell it as it was spelt in the reading task. Each target was repeated twice by the experimenter. We scored the number of correct spellings for the entire target pseudo-words and for the complex graphemes of each syllable.

\section{Orthographic choice task}

Each child was given three homophonic alternative spellings for each target pseudo-word: (1) the original target spelling previously seen (called hereafter, target pseudo-word; e.g., baitare in Set A), (2) a homophonic spelling in which the two target complex graphemes were replaced by two other complex graphemes which had been seen in two other pseudo-words of the same set (hereafter, complex homophone; e.g., beitart) and corresponded to the other set target spelling, and (3) another homophonic spelling in which the two complex graphemes were replaced by the most frequent graphemes for these target phonemes in French (hereafter, simple homophone; e.g., bétar). The 14 triplets for each target item were printed on a sheet of paper in 16-point Arial font with 1.5-line spacing. The triplets were randomly arranged across the page and the three homophones randomly ordered within each triplet. For each group of three homophones, 
the experimenter asked the child to circle the pseudo-word that was spelt like in the reading task.

\section{Procedure}

Children were tested individually in two separate sessions in a quiet room of the school. The two sessions of approximately 20 minutes were 7 days apart.

The 88 participants were randomly allocated to set A or set B. Forty-five children (14 in third grade, 16 in fourth grade and 15 in fifth grade) read the 14 pseudo-words of set A, 43 children read the other set (17, 12 and 14 respectively). Seventeen third graders, 14 fourth graders and 13 fifth graders read subset 1 in LW condition and subset 2 in SW condition. For the other children (14, 14 and 16 respectively), the LW and SW conditions were reversed.

Session 1 began with the Alouette reading test (Lefavrais, 1965) used to determine the participants' reading age. Then, the children were familiarized with the task and trained on 10 simple bisyllabic pseudo-words, from which half was presented in the LW condition, the other half in the SW condition. Children were asked to read silently the first syllable, then to press the space bar to discover the second syllable and lastly articulate the entire pseudo-word as soon as possible. Feedback was given during the training phase. During the experimental task, each child read 56 items, consisting of 14 pseudo-words (7 in each of the LW and SW condition) that were presented 4 times each, in a random order. Reading errors were recorded by the experimenter. Two latencies were taken into account for each trial. First, the software registered latency between the first screen input and the space bar pressure. This latency corresponds to the first screen duration and was conditioned both by the first syllable silent reading speed and by motor 
time to press the space bar (hereafter first syllable processing speed). The second latency -- measured between the second screen input and the beginning of articulation -corresponds to the second screen duration and was taken as a naming speed measure (hereafter naming speed).

Seven days after session 1, the participants were presented with the spelling to dictation and orthographic choice tasks evaluating their orthographic learning of the 14 target pseudo-words.

\section{Results}

\section{Preliminary Analyses}

Preliminary analyses were carried out to assess whether pseudo-word reading accuracy, first syllable processing speed and naming speed differed according to grade or window size condition (LW vs. SW). Data from incorrectly read items were excluded from the speed analyses. For the naming speed analysis, trials with voice key errors were excluded (1.5\% of the data). A lower cut-off was established at $150 \mathrm{~ms}$, and faster responses were deemed to be errors. The application of this cut-off resulted in the exclusion of less than $1 \%$ of the data. Independently for each grade, trials with response times that were 2 standard deviations above mean response latency were excluded $(3.9 \%$ of the data). Next, the speed measures were converted into items per second as recommended by Ratcliff (1993). 
Analyses of variance (ANOVAs) were carried out on each measure reported in Table 1. In each case, two analyses were conducted: one for participant data (F1), the other for item data (F2). Factors were Grade (three, four and five) and Condition (LW vs. SW). The percentage of pseudo-words correctly decoded during the learning phase was high $(89 \%$ on average) and equivalent across conditions $(\mathrm{F} 1(1,85)=1.6$ and $\mathrm{F} 2(1,27)=1.7$, both N.S.) and grades (both F1 $(2,85)$ and F2 $(1,54)<1)$, with no interaction effect $(\mathrm{F} 1(2$, $85)=1.3$ and $\mathrm{F} 2(2,54)=1.0$, both N.S.). A qualitative analysis of error types showed that substitutions of one phoneme were the most frequent errors $(70 \%$ in the LW condition, $61 \%$ in the SW condition). We also observed some one-phoneme addition errors (17\% in the LW condition, $20 \%$ in the SW condition). Some more complex errors involving more than one phoneme were further found (13\% in the LW condition, $19 \%$ in the SW condition). The distribution of error types slightly differed between the LW and SW conditions $\left(\chi^{2}=8.2, \mathrm{p}<.05\right)$. We also examined the distribution of errors between syllables. In the LW condition, $59 \%$ of reading errors were on first syllable, $37 \%$ on second syllable and $4 \%$ on both syllables. These percentages were respectively of 54,39 and $7 \%$ in the SW condition. Analysis showed that the distribution of errors between syllables was equivalent in the LW and SW conditions $\left(\chi^{2}=5\right.$, N.S.).

The first syllable processing speed was similar across conditions (both F1 $(1,85)$ and F2 $(1,27)<1)$. However, first syllable processing speed increased with grades $(\mathrm{F} 1$ $(2,85)=7.1, \mathrm{p}<.01 ; \mathrm{F} 2(2,54)=51.5, \mathrm{p}<.001)$, suggesting that older children were faster to silently read and/or press the space bar. There was no interaction effect (both F1 $(2,85)$ and F2 $(2,54)<1)$. Naming speed differed across grades in the by-item analysis only $(\mathrm{F} 1(2,85)<1, \mathrm{NS} ; \mathrm{F} 2(2,54)=3.4, \mathrm{p}<.05)$ and was identical whatever the 
condition (both F1 $(1,85)$ and F2 $(1,27)<1)$. There was no interaction effect $(\mathrm{F} 1(2,85)$ $=1.6$, N.S.; F2 $(2,54)<1)$

Taken together, these preliminary analyses show that pseudo-word decoding was as efficient and fast in the SW condition as in the LW condition.

\section{$\underline{\text { Spelling to dictation task }}$}

The spelling to dictation task is a very difficult task in an opaque language such as French. Indeed, each complex phoneme could be spelled with several graphemes, frequently more than three (e.g., a final /r/ could be spelled r, re, rre, rt, rd, rs). As shown on Table 2, most children failed to spell entire pseudo-words accurately in the spelling to dictation task (63\% of the participants spelled none of the entire pseudo-word correctly), so floor effects prevented the analyses on entire word spelling. However, correct spelling of complex graphemes, calculated separately for each syllable, varied from 10.6 to $26.1 \%$ (median value $=17.9$; only one participant was unable to spell any of the complex graphemes correctly). An ANOVA across participants was conducted on this measure to check whether each syllable had been as efficiently memorised during the learning phase. Grades, window size conditions and syllables position were the three variables entered in the analysis. As window condition was expected to influence entire word acquisition, no main effect of window condition was expected on single grapheme scores. However, as the first syllable was exposed for a longer duration in the large window condition, we controlled whether the complex grapheme of the first syllable was better memorised in the large window condition than in the small window condition.

The analysis revealed a significant main effect of syllable position $(F(1,85)=$ $38.6, \mathrm{p}<.001$ ), showing that the second syllable was systematically memorised more 
efficiently than the first syllable. No other variable or interaction was significant, suggesting that the first syllable was not processed differently in the large window and in the small window condition.

Insert Table 2 about here

\section{Orthographic choice task}

Three series of analyses were conducted to explore the orthographic choice task results. First, the effects of grade and window size were analysed using an ANOVA across participants (Table 3). Secondly, a mixed model analysis assessed whether the window size effect influenced orthographic learning beyond the contribution of reading skills. Finally, the relation between window size effect and correct decoding during the learning phase was explored in a by-item analysis (Table 4).

\section{Grade and window size effects}

The pseudo-word orthographic choice task required the child to recognise the orthographic form of the target pseudo-word among three homophonic spellings: target, complex homophone (from the other set) and simple homophone. Results are presented in Table 3. Chi-square tests indicated that responses were not evenly distributed across the three alternatives in the different grade and window size conditions (respectively for each column of Table $3: \chi^{2}(2)=26, \mathrm{p}<.001 ; 23.1, \mathrm{p}<.001 ; 6.9, \mathrm{p}<.05 ; 12.8, \mathrm{p}<.01$; 26.3, $\mathrm{p}<.001$ and 12.1, $\mathrm{p}<.01)$. As shown in Table 3, third graders chose the simple homophone more often than the other items and fifth graders chose the target more often. 
Globally, participants did not choose at random. The general tendency was to choose the simplest homophone when the target was not recognised.

Insert Table 3 about here

A two-way ANOVA with repeated measures was performed on correct responses in the orthographic choice task. The independent variables were Grade (3-4-5) and Window Size (LW vs. SW). Results showed a significant main effect of Grade $(F(2,85)=$ $4.9, \mathrm{p}<.01)$ showing that the higher the grade, the better the targets were recognised. More importantly, the Window Size effect was significant $(F(1,85)=5.9, p<.05)$, showing that target pseudo-words were better recognised following the LW condition than the SW condition. The Window Size by Grade interaction was not significant $(\mathrm{F}(2,85)<1)$. Therefore, results provide no evidence that Grade modulates the effect of Window Size on target recognition.

\section{$\underline{\text { Window size effect and reading skills }}$}

We further controlled whether window size influenced orthographic learning beyond the influence of pseudo-word decoding accuracy and reading speed as measured during the learning phase. A linear mixed model analysis was conducted to test the prediction that window size accounted for orthographic learning, after control of both pseudo-word accuracy, first syllable processing speed, reading speed and total processing duration (i.e., time between the onset of the first screen and the offset of the second screen). In the mixed model, random factors, namely variability across participants and 
variability across items, were further controlled. Once random factors, pseudo-word accuracy, speed measures and item duration were taken into account, window size remained as a significant predictor of performance in the orthographic choice task $(\beta=$ $.32, \mathrm{p}<.05)$, showing that the window size effect is effective beyond the contribution of reading skills, total duration of item or variation between participants or between items. The three reading speed measures were also significantly included in the equation: first syllable processing speed $(\beta=-.34, \mathrm{p}<.05)$, reading speed $(\beta=-.41, \mathrm{p}<.01)$ and total processing duration $(\beta=.49, \mathrm{p}<.05)$. Reading accuracy was not $(\beta=-.06, \mathrm{~ns})$. This result replicates Nation et al. (2007)'s findings: the relation between decoding accuracy and orthographic learning does not hold at an item-by-item level when variability across participants is controlled.

\section{Window size and decoding accuracy at the item level}

We conducted a by-item analysis to assess whether the association between window size condition and target orthographic learning was equivalent or not depending on successful or unsuccessful decoding of the target. We computed a within-item variable named Decoding Difficulty with two levels: correct decoding (i.e., when a target was decoded correctly by a child on each of the 4 exposures) and incorrect decoding (i.e., when a target was decoded incorrectly on at least 1 exposure). This variable was then entered into a 2 × 2 ANOVA along with Window Size (LW vs. SW) as another withinitem factor. Results were collapsed across grades since we previously found in the byparticipants analyses that the impact of window size on target recognition was not influenced by grade. The dependent variable was the number of participants who 
accurately recognised target pseudo-words in the orthographic choice task. Descriptive statistics are shown in Table 4 ("correct" columns).

Insert Table 4 about here

The main effect of window size was marginally significant $(\mathrm{F}(1,27)=4, p=.057)$. Unsurprisingly, the main effect of decoding difficulty was significant $(\mathrm{F}(1,27)=79, p<$ $.001)$, since $87 \%$ (414/474) of the recognised items had been correctly decoded during the learning phase. The Decoding Difficulty by Window Size interaction also was significant $(\mathrm{F}(1,27)=4.6, p<.05)$. Planned comparisons revealed that target pseudowords were better recognised following the LW condition than the SW condition but only when targets had been decoded accurately $(\mathrm{F}(1,27)=4.9, p<.05 ; \mathrm{F}<1$ for the incorrectly decoded targets). Thus, visual processing of the whole letter string only affects orthographic learning when decoding has been successful.

\section{General Discussion}

This paper explored the role of whole-word visual processing on lexical orthographic learning via self-teaching in French children. As the self-teaching hypothesis is founded on the idea that phonological decoding skills are the sine qua non to acquire lexical orthographic knowledge in long-term memory, we systematically controlled target's decoding accuracy and pseudo-word decoding speed during the exposure phase. The self-teaching hypothesis also predicts that, beyond decoding skills, other cognitive processes could be important for acquiring item-specific orthographic 
information. These other cognitive processes are frequently referred to as visualorthographic processing, but they remain largely under-specified. The present study explored the issue of a complementary role of whole-word visual processing in the selfteaching process. Our main hypothesis was that self-teaching depends not only on phonological recoding skills but also on the ability to process the entire word orthographic string at once during reading. Results are consistent with this hypothesis. In an orthographic choice task, item-specific orthographic recognition was found to decrease when the targets had been processed in the small window condition, a condition that preserves phonological decoding but prevents whole-word visual processing. In contrast, specific orthographic recognition is favoured in the large window condition, suggesting that whole word processing contributes to enhance orthography learning.

\section{$\underline{\text { Self-teaching and decoding skills }}$}

The current findings provide additional support for the self-teaching role of decoding skills. Indeed, both lexical orthographic recognition and first syllable decoding speed were found to increase with grade. In accordance with other self-teaching studies that have shown that orthographic learning depends on decoding accuracy (Bowey \& Muller, 2005; Cunningham, 2006; Cunningham et al., 2002; de Jong \& Share, 2007; Kyte \& Johnson, 2006; Share, 1999), our findings confirm the general assumption that orthographic learning is achieved by way of print-to-sound translation. Not only decoding accuracy but also decoding speed seems crucial for lexical orthographic acquisition. Furthermore, our findings extend previous results in showing that the self-teaching paradigm applies to complex bi-syllabic items as well. 
In line with Nation et al.'s (2007) findings, the present results did not reveal an item-by-item relation compatible with a strong version of the self-teaching hypothesis. Although orthographic learning was greater for correctly decoded items than for incorrectly decoded items, the relation between reading accuracy and orthographic learning did not hold after control for variability between participants and between items (mixed model analysis). There were many cases of correctly decoded but not recognised items, and of recognised but not correctly decoded items (Table 4). This result confirms that there are factors involved in orthographic learning beyond decoding ability (Cunningham, 2006; Cunningham et al., 2002; Nation et al., 2007; Shahar-Yames \& Share, 2008). This issue will be re-examined regarding our main results on whole-word visual processing.

\section{Self-teaching and Whole-word Visual Processing}

Our most innovative finding is that whole-word visual processing favours long-term lexical orthographic acquisition. As the self-teaching hypothesis predicts that decoding accuracy is the primary factor affecting orthographic acquisition, items' decoding accuracy was systematically compared across window size conditions. Targets decoding was as successful in the small window condition as in the large window condition. However, participants better recognised targets when decoded in the large window condition, that is when all the target pseudo-word letters were simultaneously available for processing. Moreover, both the mixed model analysis and the by-item regression analyses showed that window size affects orthographic learning beyond the influence of decoding. Results provide evidence that beyond decoding accuracy, whole-word visual 
processing affects lexical orthographic acquisition. Furthermore, the large window advantage was observed after a 7 days delay, suggesting that whole-word visual processing is involved in long-term orthographic acquisition.

Even if lexical orthographic learning was found to increase with grade, the large window condition advantage was not modulated by grade. Our prediction was that the learning condition effect would be larger in older children, because of their larger visual attention span (Bosse \& Valdois, 2009). The lack of significant interaction between grade and learning condition may suggest that visual attention span abilities allow processing entire dissyllabic words simultaneously from the third grade.

Provided that decoding accuracy may present ceiling effects for advanced readers, reading speed can be viewed as a more discriminative measure of reading efficacy, more likely to affect performance in orthographic learning. In the experiment, targets processing speed was carefully measured. Analyses demonstrated that target processing speed (both first syllable processing and naming speed) was similar whatever the window size condition. The mixed model analysis confirmed that window size accounted for orthographic learning even after control of target reading speed. Thus, neither target decoding accuracy nor target decoding speed can explain the large window size advantage we found on target recognition.

Even if the first screen and second screen duration was identical in the large and small window conditions, it is noteworthy that the first syllable was exposed for a longer duration in the large window condition than in the small window condition. Indeed, the first syllable was present on both first and second screens in the large window condition but only on the first screen in the small window condition. Then, one could argue that 
actually the window size effect we have highlighted just reflects a first syllable duration effect. However if syllable duration was the relevant factor, then we would expect first syllable processing to be favoured in the large window condition as compared to the small window condition. This duration effect would affect both reading and orthographic learning. As first evidence against this interpretation, we found that, in the learning phase, the distribution of reading error types between syllables was equivalent whatever the condition (SW or LW). As second evidence against the duration effect hypothesis, most reading errors were found to occur on the first syllable (not the second) in the large window condition. Furthermore, the mixed model analysis showed that window size remained as a significant predictor of orthographic learning, even after control of total item duration (corresponding to first syllable duration in the large window condition) and first syllable processing speed (corresponding to first syllable duration in the small window condition). Lastly, results suggest that complex graphemes were better recalled when belonging to the second syllable, regardless of window size. This was true for the large window condition as well, suggesting that the first syllable was not processed longer when remaining available all along processing. In fact, the difference between first and second syllable memorisation was similar in the large and small window conditions. Thus, the overall results suggest that neither syllable duration nor item duration can account for the effect of window size on orthographic learning. Window size thus remains as a relevant factor affecting orthographic acquisition beyond the role of decoding skills. 
We further showed that whole-word visual processing affects orthographic learning only when decoding has been successful. Such a finding suggests that whole word visual processing affects orthographic learning at a processing step subsequent to phonological decoding. Thus, whole-word visual processing might correspond to the visual-orthographic factor frequently evoked in the literature as a secondary source of variance in lexical orthographic acquisition (e.g., Share, 1995).

The finding that whole-word visual processing favours long-term lexical orthographic acquisition fits well with the learning process of the theoretical model of polysyllabic word reading of Ans et al. (1998; see Valdois et al., 2004). In this model, whole-word orthographic learning corresponds to the creation of a word-trace in episodic memory. This creation occurs every time the whole input word phonological and orthographic information is simultaneously available for processing. In a self-teaching situation, sub-lexical units are sequentially decoded for the entire phonological form of the input word to be generated as output at the end of analytic processing. In the theoretical model, analytic processing relies on a narrow visual attentional window that focuses on each of the relevant sub-lexical units of the input in turn. At the end of analytic processing, the entire phonological form of the input item is made available in phonological short-term memory but the corresponding unit has to be reactivated at the input orthographic level. This requires the visual attentional window to extend over the entire orthographic sequence of the input word, so leading to strengthen the links between the whole orthographic and phonological units for the creation of a new word-trace in long term memory. In our experiments, a reallocation of visual attention on the entire 
input sequence was prevented in the small window condition, thus predicting poorer orthographic learning.

The VA span was introduced as the psychological counterpart of the theoretically defined visual attentional window (Bosse et al., 2007). A reduced VA span was found to characterize some dyslexic children who otherwise demonstrated very poor orthographic knowledge (Dubois et al, 2007; Valdois et al., 2003; Valdois et al., 2011). We further showed that a substantial number of dyslexic children exhibited impaired VA span capacities which accounted for a significant amount of variance in reading when partialing out their phonological abilities (Bosse et al., 2007). Actually, variability of VA span exists among typically developing children and explains a significant part of irregular word reading (Bosse \& Valdois, 2009) and spelling (Bosse \& Valdois, 2008) variability. Both theoretical data and empirical findings thus suggest that the VA span might play a key role in word specific orthographic acquisition and self-teaching. However, we acknowledge that the current findings are not direct evidence that the benefit provided by whole word processing relies on VA span skills. Further studies are needed to confirm that VA span relates to whole-word orthographic learning by selfteaching.

To summarise, the present study explored whether differences in visual processing modulated orthographic learning by self-teaching in French third to fifth grade children. The essential and novel contribution of the current study is to provide evidence that whole-word visual processing improves orthographic learning. Indeed, orthographic learning is enhanced when all the letters of correctly decoded targets are simultaneously 
available for processing, in comparison with learning situations in which they are only discovered in turn. The whole-word visual processing advantage pointed out in the current study strongly suggests that beyond decoding ability, orthographic learning could further depend on child's visual attention span abilities. 
Table 1

Pseudo-word Reading Accuracy and Reading Speed (mean and SD) during the learning phase, as a Function of Grades (3rd, 4th, and 5th grades) and Window Size (Large Window (LW) vs. Small Window (SW) Conditions)

\begin{tabular}{|c|c|c|c|c|c|c|}
\hline & \multicolumn{2}{|c|}{ Grade 3} & \multicolumn{2}{|c|}{ Grade 4} & \multicolumn{2}{|c|}{ Grade 5} \\
\hline & $\begin{array}{c}\text { LW } \\
\text { condition }\end{array}$ & $\begin{array}{c}\text { SW } \\
\text { condition }\end{array}$ & $\begin{array}{c}\text { LW } \\
\text { condition }\end{array}$ & $\begin{array}{c}\text { SW } \\
\text { condition }\end{array}$ & $\begin{array}{c}\text { LW } \\
\text { condition }\end{array}$ & $\begin{array}{c}\text { SW } \\
\text { condition }\end{array}$ \\
\hline$\%$ reading accuracy & $89(12)$ & $91(8)$ & $91(11)$ & $87(12)$ & $90(11)$ & $88(13)$ \\
\hline $\begin{array}{l}\text { First syllable processing } \\
\text { speed (syllable per } \\
\text { second) }\end{array}$ & $.79(.26)$ & $.79(.27)$ & $.92(.22)$ & $.91(.21)$ & $1.03(.27)$ & $1.04(.28)$ \\
\hline $\begin{array}{l}\text { Reading speed (PW per } \\
\text { second) }\end{array}$ & $1.25(.43)$ & $1.23(.43)$ & $1.34(.51)$ & $1.30(.52)$ & $1.33(.32)$ & $1.37(.39)$ \\
\hline
\end{tabular}


Table 2

Spelling to dictation task: Mean percentage (and standard deviation) of accurately spelled target graphemes as a Function of Syllabe position, Grades and Window Size (LW vs. SW Conditions), and accurately spelled Pseudo-words.

\begin{tabular}{|l|l|l|l|l|l|l|}
\hline & \multicolumn{2}{|c|}{ Grade 3 } & \multicolumn{2}{c|}{ Grade 4 } & \multicolumn{2}{c|}{ Grade 5 } \\
\hline & LW & SW & LW & SW & LW & SW \\
& condition & condition & condition & condition & condition & condition \\
\hline First syllable & $14.7(17.1)$ & $10.6(11.6)$ & $16.3(15.9)$ & $11.7(14)$ & $15.3(14.3)$ & $17.7(16.5)$ \\
\hline Second syllable & $19.4(14.1)$ & $19.4(11.4)$ & $23.5(16.1)$ & $18.9(10.3)$ & $25.1(18.2)$ & $26.1(14.8)$ \\
\hline Entire pseudo-word & $2.8(6.8)$ & $1.4(5.7)$ & $4.6(7.8)$ & $3.1(6)$ & $5.4(11.7)$ & $5.9(9)$ \\
\hline
\end{tabular}


Table 3

Orthographic choice task: Mean Percentage (and standard deviation) of orthographic choice on each pseudo-word type, as a Function of Grades and Window Size (LW vs. SW Conditions)

\begin{tabular}{|l|l|l|l|l|l|l|}
\hline & \multicolumn{2}{|c|}{ Grade 3 } & \multicolumn{2}{c|}{ Grade 4 } & \multicolumn{2}{c|}{ Grade 5 } \\
\hline & LW & SW & LW & SW & LW & SW \\
& condition & condition & condition & condition & condition & condition \\
\hline Orthographic Choice & & & & & & \\
(1) target & $35(18.4)$ & $28.6(23.9)$ & $40.8(20.5)$ & $35.7(22.5)$ & $50.2(22.5)$ & $41.4(22)$ \\
\hline (2) complex homophone & $18.4(16.6)$ & $23(15.1)$ & $25.5(16.7)$ & $21.9(17.2)$ & $23.6(13.9)$ & $22.2(15.1)$ \\
\hline (3) simple homophone & $46.5(19.9)$ & $48.4(27.8)$ & $33.7(22.1)$ & $42.3(25)$ & $26.1(21.3)$ & $36.5(22.8)$ \\
\hline
\end{tabular}


Table 4

Total Number of Correctly and Incorrectly Recognised Items in the Orthographic Choice Task, as a Function of Window Size (LW vs. SW conditions) and Decoding Difficulty (Correctly vs. Incorrectly Decoded) During the Reading Phase.

\begin{tabular}{|l|c|c|c|c|}
\hline & \multicolumn{2}{|c|}{ LW condition } & \multicolumn{2}{c|}{ SW condition } \\
& Correctly & Incorrectly & Correctly & Incorrectly \\
& recognised & recognised & recognised & recognised \\
\hline Correctly Decoded & 227 & 323 & 187 & 352 \\
\hline Incorrectly Decoded & 31 & 35 & 29 & 48 \\
\hline
\end{tabular}


Appendix

Experimental pseudo-words, complex graphemes in bold

\begin{tabular}{|c|c|c|}
\hline & \multicolumn{2}{|c|}{ Experiment 2} \\
\hline & SET A & SET B \\
\hline & homophone & homophone \\
\hline \multirow[t]{7}{*}{ Subset 1} & pauffou & pôphou \\
\hline & baitare & beitart \\
\hline & quavonne & kavaune \\
\hline & cipulle & scipule \\
\hline & daintho & deintto \\
\hline & ryteau & rhitau \\
\hline & hanlouque & henlouk \\
\hline \multirow[t]{7}{*}{ Subset 2} & deiphon & daiffon \\
\hline & kaltart & qualtare \\
\hline & sciraune & cironne \\
\hline & teingule & taingulle \\
\hline & bôtti & bauthi \\
\hline & rhinak & rynaque \\
\hline & henchau & hancheau \\
\hline
\end{tabular}




\section{References}

Ans, B., Carbonnel, S., \& Valdois, S. (1998). A connectionist multi-trace memory model of polysyllabic word reading. Psychological Review, 105, 678-723.

Beech, J. R., \& Harris, M. (1997). The prelingually deaf reader: A case of reliance on direct lexical access? Journal of Research in Reading, 29, 105-121.

Bosman, A. M. T., \& Van Orden, G. C. (1997). Why spelling is more difficult than reading. In C. A. Perfetti, L. Rieben, \& M. Fayol (Eds), Learning to spell. Hillsdale, N.J.: Lawrence Erlbaum.

Bosse, M.-L., Tainturier, M.-J., \& Valdois, S. (2007). Developmental dyslexia: the Visual Attention Span hypothesis. Cognition, 104, 198-230.

Bosse, M.-L., \& Valdois, S. (2008, March). Orthographic acquisition depends on early visual attention span: A longitudinal study. Paper presented at the $7^{\text {th }}$ British Dyslexia Association International Conference, Harrogate, UK.

Bosse M.-L., \& Valdois, S. (2009). Influence of the visual attention span on child reading performance: A cross-sectional study. Journal of Research in Reading, 32, 230253.

Bowey, J. A., \& Muller, D. (2005). Phonological recoding and rapid orthographic learning in third-graders' silent reading: a critical test of the self-teaching hypothesis. Journal of Experimental Child Psychology, 92, 203-219.

Castles, A., \& Nation, K. (2006). How does orthographic learning happen? In S. Andrews (Ed.), From inkmarks to ideas: Challenges and controversies about word recognition and reading. London: Psychology Press. 
Castles, A., \& Nation, K. (2008). Learning to be a good orthographic reader. Journal of Research in Reading, 31, 1-7.

Cunningham, A. E. (2006). Accounting for children's orthographic learning while reading text: Do children self-teach? Journal of Experimental Child Psychology, 95, 5677.

Cunningham, A. E., Perry, K. E., Stanovich, K. E., \& Share, D. L. (2002). Orthographic learning during reading: Examining the role of the self-teaching. Journal of Experimental Child Psychology, 82, 185-199.

de Jong, P. F., \& Share, D. L. (2007). Orthographic learning during oral and silent reading. Scientific Studies of Reading, 11, 55-71.

Dubois, M., Lafaye de Micheaux, P., Noël, M.P. \& Valdois, S. (2007). Pre-orthographical constraints on visual word recognition: Evidence from a case study of developmental surface dyslexia. Cognitive Neuropsychology, 24(6), 623-660.

Ehri, L. C. (2005). Learning to read words: Theory, findings, and issues. Scientific Studies of Reading, 9, 167-188.

Jorm, A. F., \& Share, D. L. (1983). Phonological recoding and reading acquisition. Applied Psycholinguistics, 4, 103-147.

Kyte, C. S., \& Johnson, C. J. (2006). The role of phonological recoding in orthographic learning. Journal of Experimental Child Psychology, 93, 166-185.

Lassus-Sangosse, D., N'Guyen-Morel, M. A., \& Valdois, S. (2008). Sequential or simultaneous visual processing deficit in developmental dyslexia. Vision Research, 979-988. 
Lefavrais, P. (1965). Test de l'Alouette. Paris: Editions du centre de psychologie appliquée.

Martens, V. E. G., \& de Jong, P. F. (2006). The effect of visual word features on the acquisition of orthographic knowledge. Journal of Experimental Child Psychology, 93, 337-356.

Martin-Chang, S. L., Levy, B. A., \& O'Neil, S. (2007). Word acquisition, retention, and transfer: findings from contextual and isolated word training. Journal of Experimental Child Psychology, 96(1), 37-56.

Mayall, K., Humphreys, G. W., Mechelli, A., Olson, A., \& Price, C. J. (2001). The effects of case mixing on word recognition: Evidence from a PET study. Journal of Cognitive Neuroscience, 13, 1275-1286.

Mayall, K., Humphreys, G. W., \& Olson, A. (1997). Disruption to word or letter processing? The origins of case-mixing effects. Journal of Experimental Psychology: Learning, Memory and Cognition, 23(5), 1275-1286.

Nation, K., Angell, P., \& Castles, A. (2007). Orthographic learning via self-teaching in children learning to read English: Effects of exposure, durability, and context. Journal of Experimental Child Psychology, 96, 71-84.

Paul, P. (2001). Language and deafness (3rd ed.). San Diego, CA: Singular Publishing Group.

Ratcliff, R. (1993). Methods for dealing with reaction time outliers. Psychological Bulletin, 114, 510-532.

Raven, J. C., Court, J. H., \& Raven, J. (1998). Progressive matrices standard (PM38). Paris: EAP. 
Rayner, K. (1986). Eye movements and the perceptual span in beginning and skilled readers. Journal of Experimental Child Psychology, 41, 211-236.

Schneider, W., Eschman, A., \& Zuccolotto, A. (2002). E-Prime reference guide. Psychology Software Tools, Inc.

Share, D. L. (1995). Phonological recoding and self-teaching: Sine qua non of reading acquisition. Cognition, 55, 151-218.

Share, D. L. (1999). Phonological recoding and orthographic learning: A direct test of the self-teaching hypothesis. Journal of Experimental Child Psychology, 72, 95-129.

Share, D. L. (2004). Orthographic learning at a glance: on the time course and developmental onset of self-teaching. Journal of Experimental Child Psychology, 87(4), 267-298.

Share, D. L. (2008). Orthographic learning, phonological recoding, and self-teaching. Advances in Child Development and Behavior, 36, 31-82.

Stanovich, K. E. (1993). The language code: Issues in word recognition. In S. R. Yussen \& M. C. Smith (Eds.), Reading across the life span (pp. 111-135). New York: Springer-Verlag.

Valdois, S., Bidet-Ildei, C., Prado, C., Lassus-Sangosse, D., Guinet E. \& Orliaguet, J.P. (2011). A visual processing but no phonological disorder in a child with mixed dyslexia. Cortex, 47, 1197-1218.

Valdois, S., Bosse, M.-L., Ans, B., Carbonnel, S., Zorman, M., David, D., \& Pellat, J. (2003). Phonological and visual processing deficits can dissociate in developmental dyslexia: Evidence from two case studies. Reading and Writing: An Interdisciplinary Journal, 16, 541-572. 
Valdois, S., Bosse, M.-L., \& Tainturier, M.-J. (2004). The cognitive deficits responsible for developmental dyslexia: Review of evidence for a selective visual attention disorder. Dyslexia, 10, 1-25. 


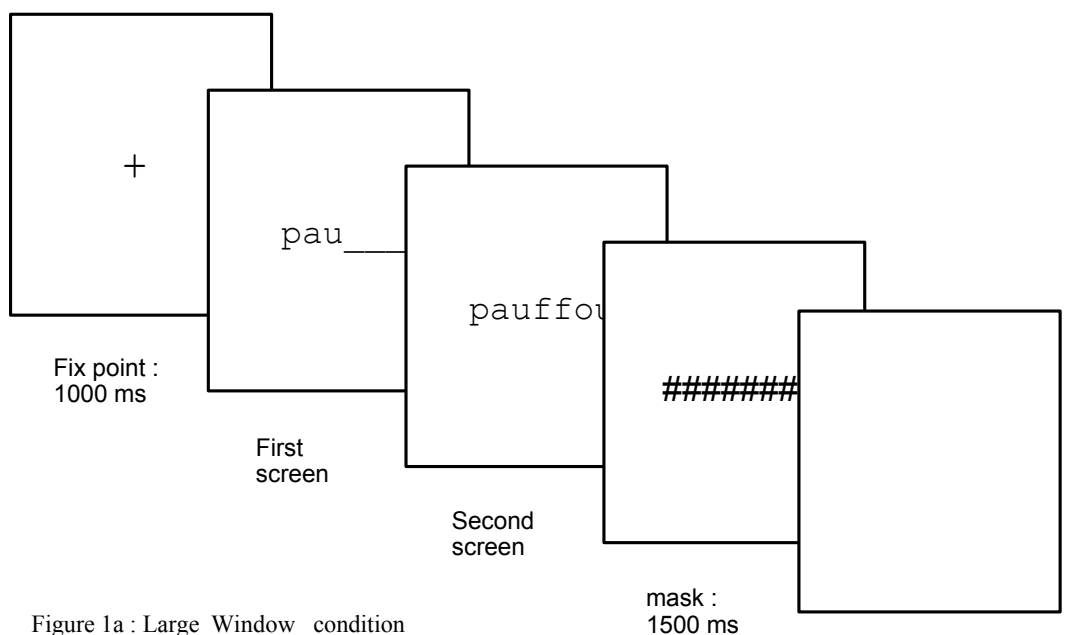

Figure 1a : Large Window condition

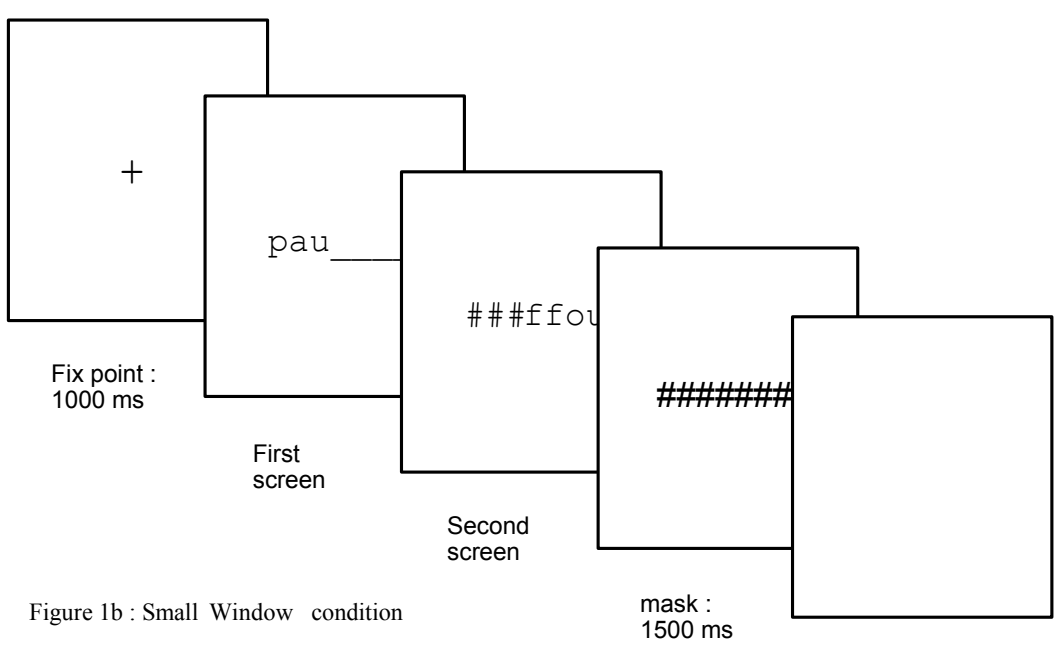

Figure 1: Conditions of pseudo-word presentation; large window (Fig. 1a), small window (Fig. 1b). 